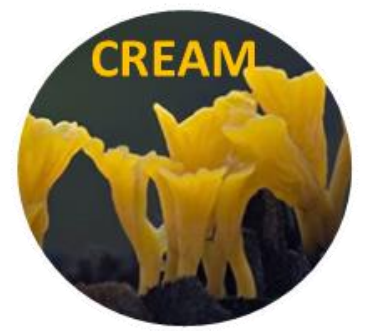

Current Research in Environmental \& Applied Mycology 6 (4): 256-267(2016) ISSN 2229-2225

www.creamjournal.org

Article

CREAM

Copyright $@ 2016$

Doi 10.5943/cream/6/4/3

Online Edition

\title{
Stimulation of the production of new volatile and non-volatile metabolites by endophytic Aspergillus niger using small organic chemicals
}

\section{Toghueo KRM ${ }^{1 *}$, Dinkar $S^{2}$ and Boyom FF ${ }^{1}$}

\begin{abstract}
${ }^{1}$ Antimicrobial and Biocontrol Agents Unit (AmBcAU), Laboratory for Phytobiochemistry and Medicinal Plants Studies, Department of Biochemistry, Faculty of Science, University of Yaoundé I, P.O. Box 812, Yaoundé, Cameroon.

${ }^{2}$ Malaria Research Laboratory, International Centre for Genetic Engineering and Biotechnology, Aruna Asaf Ali Marg, New Delhi 110067, India.
\end{abstract}

Toghueo KRM, Dinkar S, Boyom FF 2016 - Stimulation of the production of new volatile and nonvolatile metabolites by endophytic Aspergillus niger using small organic chemicals. Current Research in Environmental \& Applied Mycology 6 (4): 256-267, Doi 10.5943/cream/6/4/3

\begin{abstract}
This study was designed to observe the effect of small organic chemicals on the production of volatile and non-volatile metabolites by an endophytic strain of Aspergillus niger isolated from the roots of Terminalia catappa Linn. (Tropical-almond, Combretaceae). The fungus was cultured for 6 days at $25^{\circ} \mathrm{C}$ in static condition in potato dextrose broth (PDB), supplemented with $1 \%$ acetone, $1 \%$ DMSO, $1 \%$ ethanol, and $1 \mu \mathrm{M}$ 5-azacytidine. The ethyl acetate extracts were analyzed by high performance liquid chromatography (HPLC) and gas chromatography coupled with mass spectrometry (GC-MS). Results of HPLC analysis showed increased content of many compounds in PDB culture supplemented with 5-azacytidine, while supplementation with acetone led to a new compound at retention time ( $\mathrm{RT} \approx 35.87 \mathrm{~min}$ ), as well as $\mathrm{DMSO}$, and ethanol ( $\mathrm{RT} \approx 38.05 \mathrm{~min}$ ). The GC-MS analysis of the ethyl acetate extract of untreated A.niger showed the presence of 6 volatile metabolites of which oxalic acid, isobutyl propyl ester was the most abundant compound (60.79\%). The chromatographic profile of extracts from A. niger cultured with acetone, DMSO, ethanol and 5-azacytidine showed 12, 16, 14 and 13 volatile compounds respectively. Cyclohexanecarboxaldehyde,3,3-dimethyl-5-oxo- was the most abundant compound representing $58.21 \%, 40.12 \%$ and $64.38 \%$ in acetone, DMSO and ethanol supplemented cultures extracts respectively. For the 5-azacytidine treated fungus, 9-octadecenoic acid (Z)- $(26.91 \%)$ and tetradecanoic acid, 12-methyl-, methylester $(21.35 \%)$ were the most abundant. In addition, a new unidentified compound was detected in the extract of 5-azacytidine treated fungus. This study highlights the potential of small organic chemicals to increase the yield and to stimulate the production of new secondary metabolites by A. niger.
\end{abstract}

Keywords - Aspergillus niger - endophytic fungi - GC-MS - HPLC - small organic chemicals Terminalia catappa

\section{Introduction}

Natural products are an unsurpassed source of bioactive compounds and constitute a relevant economic resource for the pharmaceutical, cosmetic and food industry (Baker et al. 2000). Medicinal plants provide a unique environment for microorganisms and have been recognized as a repository of endophytes with novel metabolites (Strobel et al. 2004). Endophytic fungi provide a wide variety of structurally unique, and bioactive natural products representing a huge reservoir which offers an 
enormous potential for exploitation for medicinal, agricultural and industrial uses (Tan \& Zou 2001, Schulz et al. 2002, Strobel \& Daisy 2003, Zhang et al. 2006).

Aspergilli represent a large number of species which are a rich source of secondary metabolites (Schneider et al. 2008); they can harbour 30-50 distinct polyketide synthase (PKS) and non-ribosomal peptide synthase (NRPS) gene clusters per species (Payne et al. 2006). They are known to produce antimicrobial secondary metabolites like helvolic acid, monomethylsulochrin, ergosterol and $3 \beta$ hydroxy-5 $\dot{\alpha}$ ergosterol (Gao et al. 2007), cytotoxin, brefeldin A (Wang et al. 2002), tensyuic acid, nigerazine B, tensidol A, and ochratoxin (Nielsen et al. 2009, Al-Shaibani et al. 2013). Many studies have described the antimicrobial potential of endophytic Aspergillus spp. against a panel of clinically significant human pathogens (Maria et al. 2005, Tayung \& Jha 2007, Kumar et al. 2010, Toghueo et al. 2016).

However, Aspergilli possess a greater number of gene clusters encoding for the production of secondary metabolites than the number of natural products that have been isolated from these same organisms (Fisch et al. 2009, Scherlach \& Hertweck 2009, Zerikly \& Challis 2009). These transcriptionally suppressed gene clusters, are collectively referred to as silent biosynthetic pathways, generally unexpressed under a variety of laboratory culture conditions. In fact, Fisch et al. (2009) reported that in Aspergillus niger fewer than $30 \%$ of its biosynthetic gene clusters are transcribed under a variety of in vitro culture conditions. These silent biosynthetic pathways are anticipated to be a rich source of chemically diverse compounds (e.g. novel organic moieties, multifaceted stereochemical features, unique heteroatom incorporation, etc.) with outstanding potential for generating novel therapeutic leads.

Many strategies have been applied to stimulate the expression of these silent pathways and to promote secondary metabolite biosynthesis. These strategies include to vary medium and growth conditions (Bode et al. 2002), exchange of native gene promoters with constitutive or inducible promoters or overexpression of transcription factors (Brakhage \& Schroeckh 2011), co-cultivation with one or more microorganisms (Combès et al. 2012, Marmann et al. 2014), fermentation in the presence of non-ionic adsorption resins (De la Cruz et al. 2012), and addition of small-molecule elicitors such as epigenetic modifiers (William et al. 2008) or organic solvents (Pettit 2011). Therefore, the aim of this study was to investigate the effects of different small organic chemicals on the production of volatile and non-volatile compounds by an endophytic strain of Aspergillus niger isolated from the roots of Terminalia catappa.

\section{Materials and Methods}

\section{Isolation and morphologic identification of endophytic fungi}

A root sample of T. catappa (National Herbarium Voucher Specimen number 51244/HNC) was collected on the University of Yaoundé 1 main campus (September, 2014). Small root pieces, measuring about $2 \mathrm{~mm}$ were surface disinfected with $70 \%$ ethanol for $5 \mathrm{~min}$, followed by treatment with a $1 \%$ active chlorine solution for $15 \mathrm{~min}, 2 \mathrm{~min}$ in $70 \%$ ethanol, and a final rinse with sterile distilled water (3 times). Fifteen disinfected root pieces were plated on potato dextrose agar (PDA) containing chloramphenicol $(200 \mathrm{mg} / \mathrm{l})$ and kept in the dark at $25^{\circ} \mathrm{C}$. After mycelium emerged from plant tissues into the agar, mycelial fragments were transferred to fresh PDA plates as previously described (Sánchez Márquez et al. 2007) and maintained under natural light at room temperature. Endophytic fungi were identified up to genus level based on colony characters, growth and structure of mycelium, and conidia as described by Klich (2002).

\section{Molecular characterization}

The identification of the endophytic fungus was made using the nucleotide sequence of the ITS1-5.8S rRNA-ITS2 region. DNA was extracted from small mycelial fragments scraped from the surface of the culture plates using a commercial kit (RedExtract-N-Amp Plant PCR, Sigma Aldrich). The ITS1-5.8S rRNA-ITS2 region was amplified by PCR using primers ITS4 and ITS5 (White et al. 1990). Amplicons were sequenced with primer ITS4 (Sánchez Márquez et al. 2007). 
To identify ITS sequences similar to the one obtained from the fungal isolates, the FASTA algorithms were used to screen the EMBL/Genbank database of fungal nucleotide sequences. To visualize the diverse fungal taxa identified by means of molecular characters, a sequence similarity dendrogram was made. Isolate and reference strain (CBS, CICC strains) sequences were aligned using the program ClustalX 2.1 with the default settings, and the dendrogram was made with MEGA 6.06 software using the neighbor-joining method with Kimura 2-parameter distances. Groups of sequences at close proximity within the same branch of the dendrogram were individually aligned with ClustalX to determine their percentage of similarity. Sequences with a similarity greater than $99 \%$ were considered to belong to the same species (Sánchez Márquez et al. 2007).

\section{Endophyte culture in medium supplemented with small organic compounds}

Aspergillus niger strain TCR was first cultivated on potato dextrose agar. Mycelia pieces of 1x1 $\mathrm{mm}$ from a culture were used to inoculate $20 \mathrm{~mL}$ of potato dextrose broth (potatoes in infusion $200 \mathrm{~g} / \mathrm{L}$, dextrose 20g/L, pH 5.1 \pm 0.2 ) (PD; HiMedia) in $100 \mathrm{~mL}$ erlenmeyer flasks supplemented with different organic chemicals: $1 \mu \mathrm{M}$ of 5-azacytidine (Sigma Aldrich); $1 \%$ dimethyl sulfoxide (DMSO) (Sigma Aldrich); $1 \%$ ethanol (HPLC grade, Merck); and 1\% acetone (HPLC grade, Merck), and a control without any supplementation. Liquid cultures were grown for 6 days in static condition at room temperature before extraction.

\section{Extraction from fungal cultures}

To each culture, $20 \mathrm{~mL}$ of ethyl acetate were added and shaken and kept overnight at room temperature. This mixture was then transferred to a separatory funnel, and the organic phase collected. This process was repeated thrice, resulting in a total volume of $60 \mathrm{ml}$ per sample. The ethyl acetate was evaporated at $40^{\circ} \mathrm{C}$ in a Labconco RapidVap parallel evaporation system. The residue was dissolved in 0.2-0.4 $\mathrm{mL}$ of methanol, transferred to pre-weighed microfuge tubes and evaporated to dryness. The dry residue was dissolved in methanol $(3 \mathrm{mg} / \mathrm{mL})$ before compositional analysis by HPLC and GC-MS.

\section{Analysis of non-volatile metabolites profile by high performance liquid chromatography (HPLC)}

Analysis of non-volatile metabolites was performed on a Agilent 1260 series HPLC system equipped with autosampler and diode array detector (DAD) using a Synergi $4 \mu$ Polar-RP 80A column $(250 \mathrm{~mm} \times 4.6 \mathrm{~mm})$ (Shimadzu Company). The mobile phase consisted of methanol and water, increasing linearly from $5 \%$ methanol at the time of injection to $100 \%$ at $90 \mathrm{~min}$. The flow rate was $1 \mathrm{~mL} / \mathrm{min}$ and column temperature was $40^{\circ} \mathrm{C}$. Chromatograms were recorded at $214 \mathrm{~nm}\left(\sigma-\sigma^{*}\right.$ transitions shown by several aliphatic molecules) and $254 \mathrm{~nm}\left(\pi-\pi^{*}\right.$ transition shown by aromatic molecules).

\section{Analysis of volatiles metabolite profile by gas chromatography-mass spectrometry (GC-MS)}

The GC-MS analysis was carried out on a GC-MS-QP2010 Ultra system (Shimadzu Company) comprising a AOC-20i autosampler and gas chromatograph interfaced to a mass spectrometer instrument using the following conditions: Column Rtx-5MS $(30 \mathrm{~m} \times 0.25 \mathrm{~mm}$ id $\times 0.25 \mu \mathrm{m}$ film thickness, composed of $100 \%$ Dimethyl poly siloxane), operating in electron impact mode at $70 \mathrm{eV}$; carrier gas (helium $99.999 \%$ ) at a flow rate $1 \mathrm{ml} / \mathrm{min}$; injection volume of $1 \mu \mathrm{L}$; injector temperature $260^{\circ} \mathrm{C}$; ion-source temperature $280^{\circ} \mathrm{C}$. The oven temperature was maintained at $110^{\circ} \mathrm{C}$ (isothermal for $2 \mathrm{~min}$ ), and then programmed at $10^{\circ} \mathrm{C} / \mathrm{min}$ increment to $200{ }^{\circ} \mathrm{C}$, then $5{ }^{\circ} \mathrm{C} / \mathrm{min}$ to $280^{\circ} \mathrm{C}$, and finally maintained for $9 \mathrm{~min}$ at isothermal $280^{\circ} \mathrm{C}$. Mass spectra were taken at $70 \mathrm{eV}$, a scan interval of $0.5 \mathrm{~s}$ and fragments from 40 to 550Da.

\section{Identification of bioactive compounds}

Interpretation of GC-MS mass-spectra was conducted using the database of the National Institute of Standards and Technology (NIST) having more than 62,000 patterns. Spectra of unknown components were compared with those of known components of the NIST library. The name, and molecular formula of the compounds identified were ascertained. 


\section{Results}
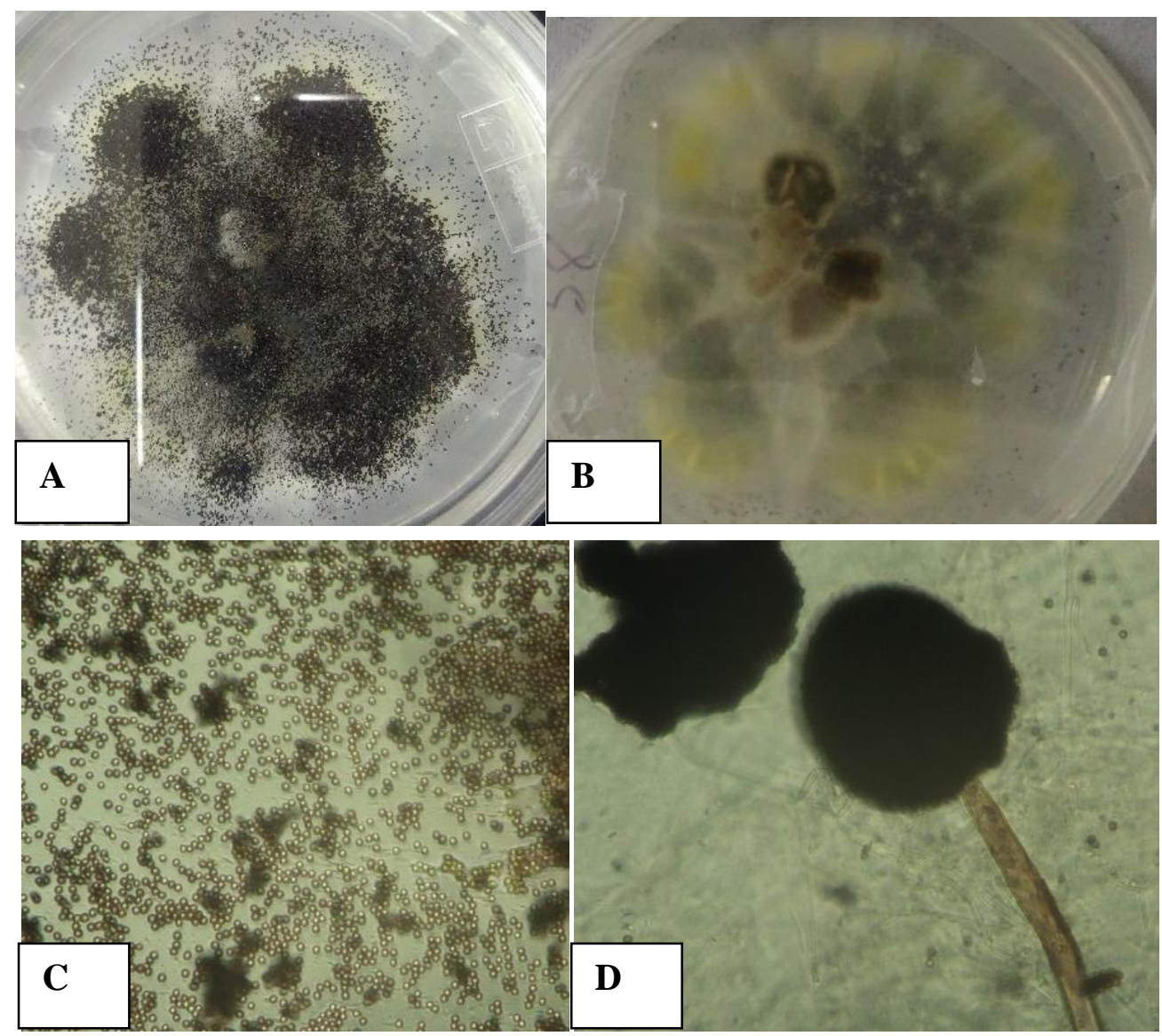

Fig. 1 - Colony of Aspergillus sp on PDA after 7 days. Colonies consist of a compact black. A. or yellow basal. B. felt covered by a dense layer of dark-brown to black conidial heads. C. Conidial dark brown. D. Septate and hyaline hyphae, and a dark conidiophore globose vesicle.

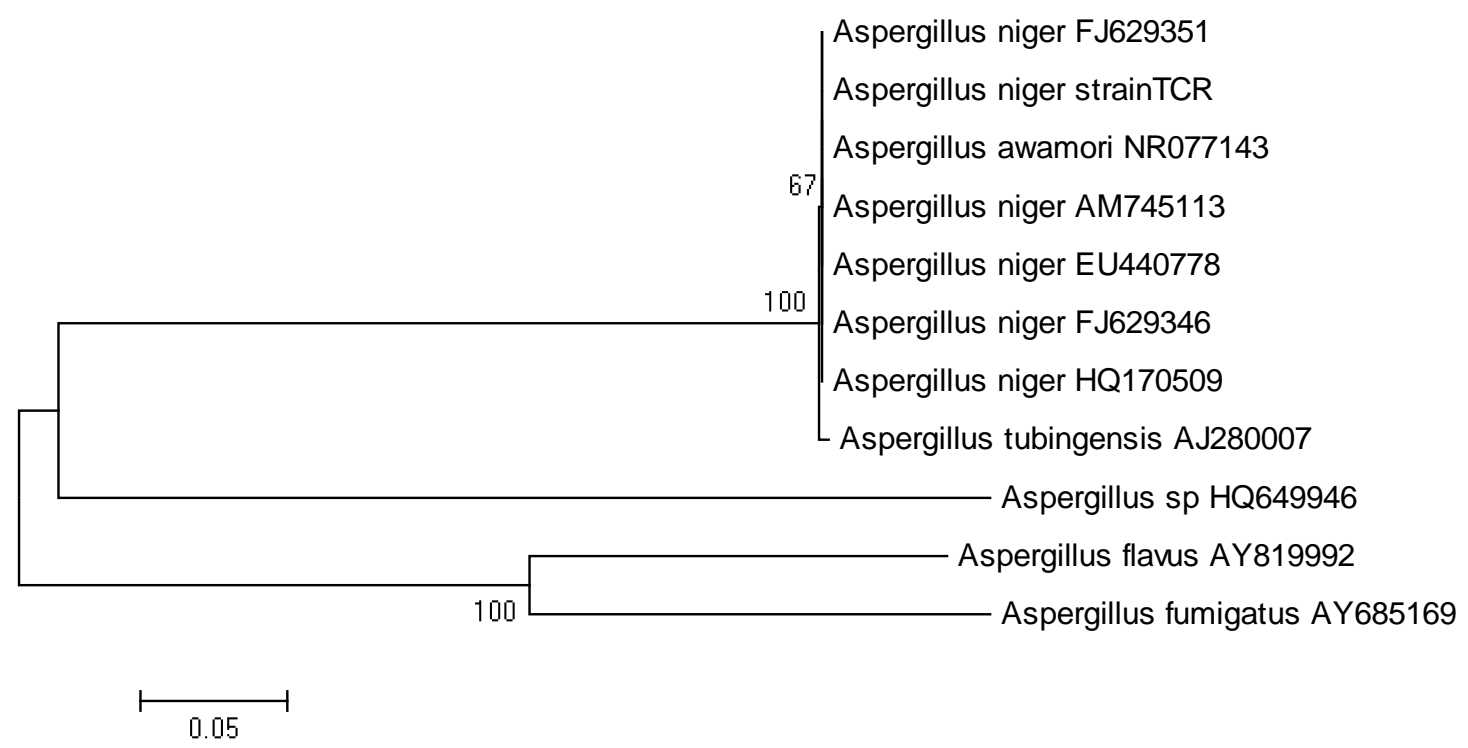

Fig. 2 - Phylogenetic tree showing relationship of Aspergillus niger strain TCR with other related fungal species. ITS1-5.8S-ITS2 sequence analyzed by neighbor-joining tree made using p-distance for nucleotides and the pairwise gap deletion option. Numbers at branch nodes are bootstrap values, indicating support based on 500 replications. 


\section{Morphological characteristics of the fungal isolate}

Colonies growing on PDA at $25 \pm 2{ }^{\circ} \mathrm{C}$ were initially white and then turned quickly into black with conidial production. The reverse was pale yellow with radial fissures in the agar. Hyphae were septate and hyaline, while the conidial heads were large, globose, and dark brown, becoming radiate and tending to split into several loose columns with time. The conidial head was biseriate. Conidiophores were long, smooth, and hyaline, becoming darker at the apex and terminating in a globose vesicle. Metulae and phialides covered the entire vesicle. Conidia were dark brown to black, very rough-walled, and globose to subglobose (Fig 1).

\section{Molecular characterization of the fungal isolate}

The isolate was identified using ITS regions of rDNA and the search for sequence similarity in BLAST nucleotide using FASTA algorithms. The isolate of Aspergillus sp gave 99\% similarity with Aspergillus niger FJ629351 and was therefore identified as Aspergillus niger (Fig 2). The phylogenetic analysis was based on the data from A. niger, together with those that presented similarity in the NCBI database, and other sequences belonging to different species, with the objective of confirming that the isolates were grouped with the families and the closest BLAST identity. The phylogenetic analysis is presented in Fig 2.

\section{Comparative HPLC profiles of non-volatile metabolites from $A$. niger}

Fig 3 shows the non-volatile metabolite profile obtained by HPLC analysis of ethyl acetate extracts of $A$. niger cultures at $25^{\circ} \mathrm{C}$ in static condition, in absence of organic chemicals (fig $3 \mathrm{~A}$ ) and in presence of acetone (fig 3B), DMSO (fig 3C), ethanol (fig 3D) and 5-azacytidine (fig 3E).

The chromatograms showed a variation in production of metabolites due to exposure to different organic chemicals. In Fig 3, the intensity of compound 1 (RT $\approx 2.9 \mathrm{~min}$ ) was found to be highly increased in the presence of DMSO, while in presence of ethanol and acetone it decreased. The production of compounds 2 ( $\mathrm{RT} \approx 29.4 \mathrm{~min})$ and $3(\mathrm{RT} \approx 46.4 \mathrm{~min})$ was inhibited in the presence of DMSO and 5-azacytidine respectively. In comparison to untreated fungus, the production of the group of compound 4 (RT $\approx 55.6 \mathrm{~min})$ increased with 5-azacytidine, and the production of compound 5 $(\mathrm{RT} \approx 61.1 \mathrm{~min})$ also increased with DMSO and 5-azacytidine. The presence of DMSO inhibited the production of compound $6(\mathrm{mAU}<<50000)(\mathrm{RT} \approx 69.3 \mathrm{~min})$ while acetone (mAU $\approx 50000)$ and ethanol $(\mathrm{mAU} \approx 140000)$ reduced its production. The presence of DMSO also impaired the production of compound 7 (RT $\approx 75.32 \mathrm{~min}$ ), and the group of compounds 8 (RT $\approx 82.39 \mathrm{~min})$ and 9 (RT $\approx 85-92 \mathrm{~min}$ ). Contrarily, the culture with 5-azacytidine significantly stimulated their production by A.niger. The production of compound 10 ( $\mathrm{RT} \approx 95.5 \mathrm{~min}$ ) was not affected by the culture additives. In general, the presence of 5-azacytidine in PDB increased the production of many compounds, while one new compound was detected in PDB supplemented with acetone $(\mathrm{RT} \approx 35.87)$, DMSO, and ethanol (RT $\approx 38.05 \mathrm{~min}$ ).

Results from the compositional analysis of extracts (table 1) showed that the small organic chemicals stimulated the production of new volatile metabolites compared to untreated A. niger cultures. In fact, the chemical profile of the extract from untreated A.niger showed the presence of 6 volatile metabolites while the culture supplementation with acetone, DMSO, ethanol and 5-azacytidine induced the production of 12,16, 14 and 13 volatile compounds respectively. Oxalic acid, isobutyl propyl ester (60.79\%) was the most abundant compound in the untreated sample while, when cultured with acetone, DMSO and ethanol, the most abundant compound was rather Cyclohexanecarboxaldehyde,3,3-dimethyl-5-oxo- representing $58.21 \%, 40.12 \%$ and $64.38 \%$ respectively. The culture with 5 -azacytidine produced two compounds with significant contents, namely 9-octadecenoic acid (Z)- (26.91\%) and tetradecanoic acid,12-methyl-, methylester (21.35\%) and also stimulated the production of one new and unidentified volatile compound ( $\mathrm{RT}=26.683 \mathrm{~min})$.

Compound $\mathrm{C}_{21} \mathrm{H}_{21} \mathrm{~N}_{3} \mathrm{O}_{5}$ was identified in untreated A. niger extract $(0.29 \%)$ and also when treated with DMSO $(0.09 \%)$ and ethanol $(0.04 \%)$ making it a molecular marker of the endophyte. Compound $\mathrm{C}_{20} \mathrm{H}_{28} \mathrm{~F}_{3} \mathrm{NO}_{3}$ was also identified in extract of untreated $(6.42 \%)$ and acetone treated fungus $(0.37 \%)$. Disulfide, dipropyl was identified in extracts from of $A$. niger cultured with acetone $(0.20 \%)$, 

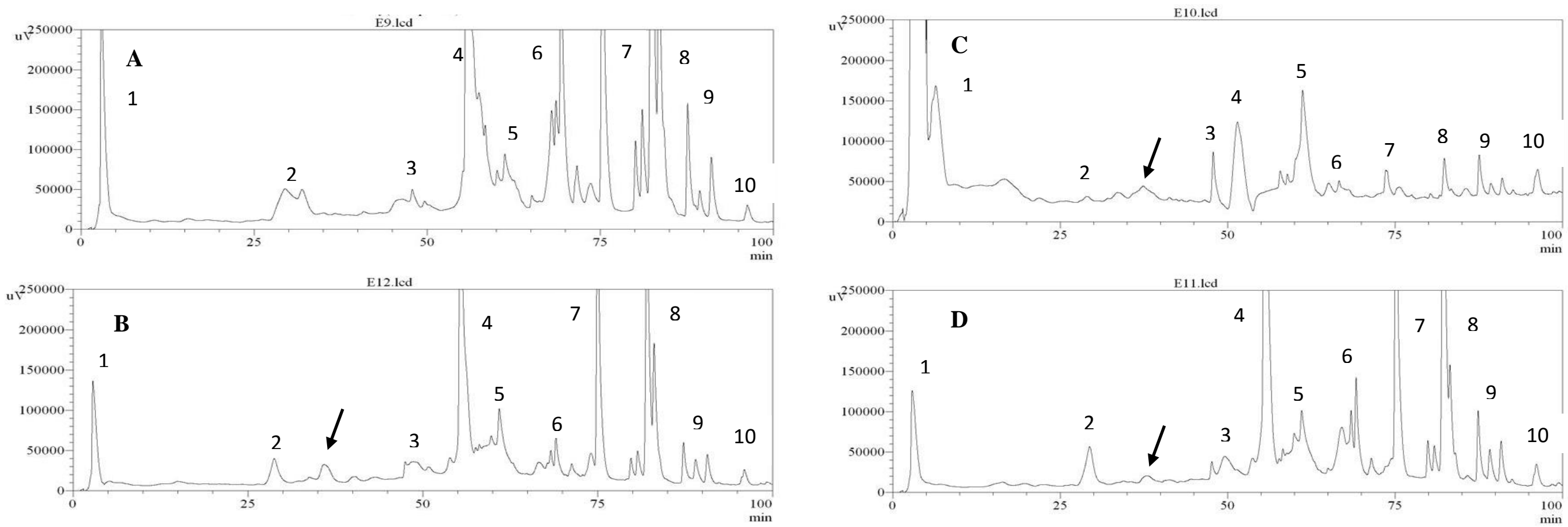

Fig. 3 - Effect of small chemicals on secondary metabolites production by A. niger

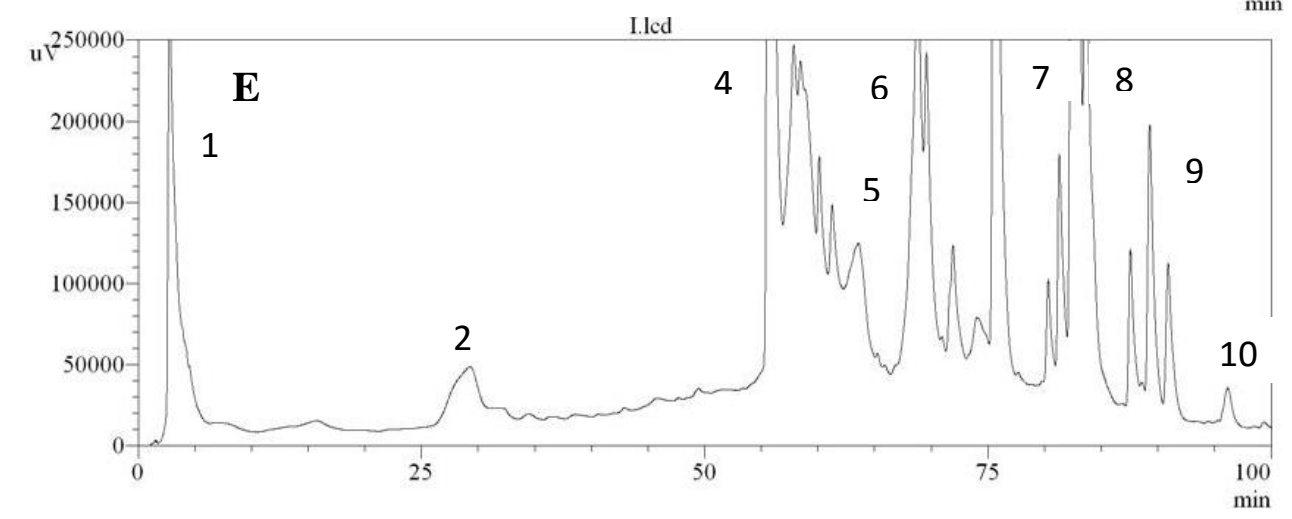


Table 1 Volatile metabolites identified by GC-MS in the ethyl acetate extract of A. niger cultured without and in the presence of acetone, DMSO, ethanol and 5-Azacytidine.

\begin{tabular}{|c|c|c|c|c|c|c|c|}
\hline \multirow[t]{2}{*}{ Chemical name } & \multirow{2}{*}{$\begin{array}{l}\text { Chemical } \\
\text { formula }\end{array}$} & \multirow{2}{*}{$\begin{array}{l}{ }_{(\mathbf{m i n})}^{1} \mathbf{R T} \\
(\mathbf{m}\end{array}$} & \multicolumn{5}{|c|}{${ }^{2}$ Abundance of compounds identified in each extract (\%) } \\
\hline & & & $\begin{array}{l}\text { Untreated } \\
\text { fungus }\end{array}$ & Acetone & DMSO & Ethanol & 5-azacytidine \\
\hline Trichloro[2.2.1.02,6]heptane, 3-bromo- & $\mathrm{C}_{7} \mathrm{H}_{9} \mathrm{Br}$ & 6.147 & & 0.43 & & & \\
\hline Propyldithyopropane & $\mathrm{C}_{6} \mathrm{H}_{14} \mathrm{~S}_{2}$ & 7.390 & & & 0.23 & & \\
\hline 3-isopropyl[3]manxine-6,9-diol & $\mathrm{C}_{17} \mathrm{H}_{25} \mathrm{NO}_{2}$ & 7.397 & & & & 0.37 & 3.67 \\
\hline Ethenone & $\mathrm{C}_{2} \mathrm{H}_{2} \mathrm{O}$ & 7.523 & & & & & 2.82 \\
\hline Phenol, 2-methyl-5-(1-methylethyl)- & $\mathrm{C}_{10} \mathrm{H}_{14} \mathrm{O}$ & 9.742 & & 9.94 & & & \\
\hline $\begin{array}{l}\text { 2-(((carbobenzyloxy)amino)methyl)-4-benzyl-5- } \\
\text { ((carbomethoxy)-amino)oxazole }\end{array}$ & $\mathrm{C}_{21} \mathrm{H}_{21} \mathrm{~N}_{3} \mathrm{O}_{5}$ & 10.293 & 0.29 & & 0.09 & 0.04 & \\
\hline 2,2-diphenyl-2,2'-BI-1,3-dioxolane & $\mathrm{C}_{18} \mathrm{H}_{18} \mathrm{O}_{4}$ & 10.299 & & 0.38 & & & \\
\hline 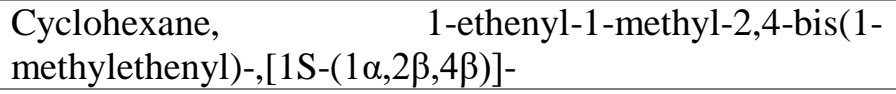 & $\mathrm{C}_{15} \mathrm{H}_{24}$ & 11.548 & & 0.34 & & & \\
\hline 1-tert-butyl-4-methyl-3-piperidinone & $\mathrm{C}_{10} \mathrm{H}_{19} \mathrm{NO}$ & 12.268 & & 2.10 & & & \\
\hline Cyclododecanecarbonitrile,1-(3-hydroxybutyl)-2-oxo, & $\mathrm{C}_{17} \mathrm{H}_{29} \mathrm{NO}_{2}$ & 12.270 & & & 4.30 & & \\
\hline 1,2,4-cyclopentanetrione,3-butyl- & $\mathrm{C}_{9} \mathrm{H}_{12} \mathrm{O}_{3}$ & 12.290 & & & & 5.20 & \\
\hline 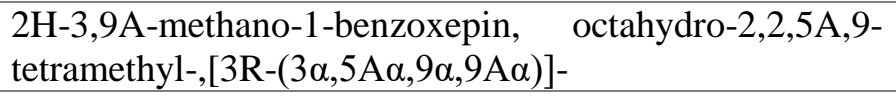 & $\mathrm{C}_{15} \mathrm{H}_{26} \mathrm{O}$ & 14.277 & & & 0.33 & & 5.49 \\
\hline 1-(propyldisulfanyl)propane & $\mathrm{C}_{6} \mathrm{H}_{14} \mathrm{~S}_{2}$ & 14.637 & & & 0.26 & & \\
\hline 1-methylcyclohex-1-en-4-carboxylic acid & $\mathrm{C}_{8} \mathrm{H}_{12} \mathrm{O}_{2}$ & 14.874 & & 15.31 & & & \\
\hline 1-oxetan-2-one,4,4-diethyl-3-methylene- & $\mathrm{C}_{8} \mathrm{H}_{12} \mathrm{O}_{2}$ & 14.877 & & & 18.63 & & \\
\hline$\Delta, 1 \alpha$-cyclohexaneacetic acid & $\mathrm{C}_{8} \mathrm{H}_{12} \mathrm{O}_{2}$ & 14.923 & & & & 21.82 & \\
\hline 2-propenyl (2,2-difluorocyclopropryl)methyl ether & $\mathrm{C}_{7} \mathrm{H}_{10} \mathrm{~F}_{2} \mathrm{O}$ & 15.759 & 1.19 & & & & \\
\hline Cyclohexanecarboxaldehyde,3,3-dimethyl-5-oxo- & $\mathrm{C}_{9} \mathrm{H}_{14} \mathrm{O}_{2}$ & 15.827 & & 58.21 & 40.12 & 64.38 & \\
\hline 1-penten-1-one,2-methyl- & $\mathrm{C}_{6} \mathrm{H}_{10} \mathrm{O}$ & 16.430 & & & 1.53 & & \\
\hline Disulfide, dipropyl & $\mathrm{C}_{6} \mathrm{H}_{14} \mathrm{~S}_{2}$ & 17.076 & & 0.20 & 0.29 & 0.08 & \\
\hline 3-hexen-2-one, 5-methyl- & $\mathrm{C}_{7} \mathrm{H}_{12} \mathrm{O}$ & 17.107 & & & 12.19 & & \\
\hline Pentanoic acid, 2-methyl & $\mathrm{C}_{6} \mathrm{H}_{12} \mathrm{O}_{2}$ & 17.115 & 7.46 & & & & \\
\hline Tetradecanoic acid, 12-methyl-, methylester & $\mathrm{C}_{16} \mathrm{H}_{32} \mathrm{O}_{2}$ & 17.123 & & & & 1.20 & 21.35 \\
\hline L-proline, N-valeryl-, undecyl ester & $\mathrm{C}_{21} \mathrm{H}_{39} \mathrm{NO}_{3}$ & 17.363 & & & 0.75 & 0.21 & 3.63 \\
\hline
\end{tabular}




\begin{tabular}{|c|c|c|c|c|c|c|c|}
\hline \multirow[t]{2}{*}{ Chemical name } & \multirow{2}{*}{$\begin{array}{l}\text { Chemical } \\
\text { formula }\end{array}$} & \multirow{2}{*}{$\begin{array}{l}{ }^{1} \mathbf{R T} \\
(\mathbf{m i n})\end{array}$} & \multicolumn{5}{|c|}{${ }^{2}$ Abundance of compounds identified in each extract (\%) } \\
\hline & & & $\begin{array}{l}\text { Untreated } \\
\text { fungus }\end{array}$ & Acetone & DMSO & Ethanol & 5 -azacytidine \\
\hline Tridecanoic acid & $\mathrm{C}_{13} \mathrm{H}_{26} \mathrm{O}_{2}$ & 17.465 & & 1.23 & & 0.63 & \\
\hline Tetradecanoic acid & $\mathrm{C}_{14} \mathrm{H}_{28} \mathrm{O}_{2}$ & 17.487 & & & 4.30 & & \\
\hline 9-octadecenoic acid (Z)- & $\mathrm{C}_{18} \mathrm{H}_{34} \mathrm{O}_{2}$ & 17.493 & & & & & 26.91 \\
\hline 5,6-dichlorohexene & $\mathrm{C}_{6} \mathrm{H}_{10} \mathrm{Cl}_{2}$ & 18.800 & & & & 0.20 & 4.87 \\
\hline 1-undecyne & $\mathrm{C}_{11} \mathrm{H}_{20}$ & 18.803 & & & 2.74 & & \\
\hline 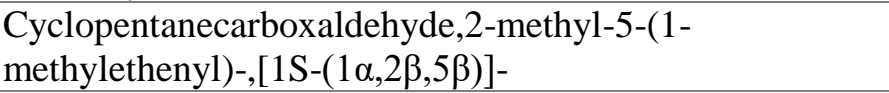 & $\mathrm{C}_{10} \mathrm{H}_{16} \mathrm{O}$ & 18.850 & & & 1.78 & & \\
\hline $\begin{array}{l}\text { (5S,8R)-5-isopropyl-8-methyl-2-methylene-3,9- } \\
\text { decadien-1-ol }\end{array}$ & $\mathrm{C}_{15} \mathrm{H}_{26} \mathrm{O}$ & 18.856 & & & & 0.28 & \\
\hline $\begin{array}{l}\text { (3R,3AS,9AR,9BR)-octahydro-3-methyl-1H- } \\
\text { furo[3'4':4,5]-isoxazolo[2,3-A]pyridin-1-one }\end{array}$ & $\mathrm{C}_{10} \mathrm{H}_{15} \mathrm{NO}_{3}$ & 18.859 & & & & & 6.05 \\
\hline Acetic acid, methylester & $\mathrm{C}_{3} \mathrm{H}_{6} \mathrm{O}_{2}$ & 19.060 & & & & & 1.46 \\
\hline Cycloheptene,5-methyl- & $\mathrm{C}_{8} \mathrm{H}_{14}$ & 19.163 & & 1.00 & & & \\
\hline 1-undecyne & $\mathrm{C}_{11} \mathrm{H}_{20}$ & 19.197 & & & & 1.36 & \\
\hline (Z,Z)-heptadeca-8,11-dien-1-yl bromide & $\mathrm{C}_{17} \mathrm{H}_{31} \mathrm{Br}$ & 19.203 & & & 9.46 & & \\
\hline 2-propenyl (2,2-difluorocyclopropyl) methyl ether & $\mathrm{C}_{7} \mathrm{H}_{10} \mathrm{~F}_{2} \mathrm{O}$ & 19.237 & & & & & 2.11 \\
\hline 2-furoic acid, but-3-yn-yl ester & $\mathrm{C}_{9} \mathrm{H}_{8} \mathrm{O}_{3}$ & 20.380 & 23.86 & & & & 11.99 \\
\hline 2-(2-furyl)-1-phenylpropane & $\mathrm{C}_{13} \mathrm{H}_{14} \mathrm{O}$ & 20.403 & & & 2.97 & & \\
\hline $\mathrm{N}$-(4-isopropylphenyl)-2-furamide & $\mathrm{C}_{14} \mathrm{H}_{15} \mathrm{NO}_{2}$ & 20.417 & & 10.49 & & 3.99 & \\
\hline Unknown compound & $* * *$ & 26.683 & & & & & 0.83 \\
\hline $\begin{array}{l}\text { 3-[6-(N- } \\
\text { benzyltrifluoromethansulfonamido)hexyl]cyclohexanone }\end{array}$ & $\mathrm{C}_{20} \mathrm{H}_{28} \mathrm{~F}_{3} \mathrm{NO}_{3} \mathrm{~S}$ & 26.721 & 6.42 & 0.37 & & & \\
\hline $\begin{array}{l}\text { 1-(cyclohexylamino)-4,5,6,7,8,9-hexahydro-10H- } \\
\text { azepino[3,2,1]indol-2-one }\end{array}$ & $\mathrm{C}_{18} \mathrm{H}_{26} \mathrm{~N}_{2} \mathrm{O}$ & 26.736 & & & & 0.23 & \\
\hline Benzocoumarin,1,2,3,8-tetramethoxy- & $\mathrm{C}_{17} \mathrm{H}_{16} \mathrm{O}_{6}$ & 26.747 & & & & & 8.81 \\
\hline Oxalic acid, isobutyl propyl ester & $\mathrm{C}_{9} \mathrm{H}_{16} \mathrm{O}_{4}$ & 28.610 & 60.79 & & & & \\
\hline
\end{tabular}

Compounds were identified through comparison of their spectra with those of known components of the NIST library; ${ }^{1}$ Retention time; ${ }^{2}$ Relative abundance of extract components was automatically generated from electronic integration of individual pics of the chromatogram relative to the total pics area; *** Unknown compound. 
DMSO $(0.29 \%)$ and ethanol $(0.08 \%)$. L-proline, $\mathrm{N}$-valeryl-,undecylester was identified in extracts from $A$. niger treated with DMSO $(0.75 \%)$, ethanol $(0.21 \%)$ and 5-azacytidine (3.63\%). Tridecanoic acid and $\mathrm{N}$-(4-isopropylphenyl)-2-furamide were identified in extracts from A. niger treated with acetone and ethanol while 5,6-dichlorohexene and 3isopropyl[3]manxine-6,9-diol were identified in extracts from fungus treated with ethanol and 5 -azacytidine. The 2-furoic acid, but-3-yn-yl ester, the most abundant compound $(23.86 \%)$ in extract of the non treated fungus, was also identified in the extract with 5-azacytidine (11.99\%). 1-undecyne was identified in extracts with DMSO (2.74\%) and ethanol (1.36\%). Overall, 3 compounds $\left(\mathrm{C}_{7} \mathrm{H}_{10} \mathrm{~F}_{2} \mathrm{O}, \mathrm{C}_{6} \mathrm{H}_{12} \mathrm{O}_{2}\right.$ and $\left.\mathrm{C}_{9} \mathrm{H}_{16} \mathrm{O}_{4}\right)$ were only identified in extract without organic supplements. Compounds $\mathrm{C}_{7} \mathrm{H}_{9} \mathrm{Br}, \mathrm{C}_{10} \mathrm{H}_{14} \mathrm{O}, \mathrm{C}_{18} \mathrm{H}_{18} \mathrm{O}_{4}, \mathrm{C}_{15} \mathrm{H}_{24}, \mathrm{C}_{10} \mathrm{H}_{19} \mathrm{NO}$, $\mathrm{C}_{8} \mathrm{H}_{12} \mathrm{O}_{2}$ and $\mathrm{C}_{8} \mathrm{H}_{14}$ were specifically stimulated in the presence of acetone. The same observation was made with compounds $\mathrm{C}_{6} \mathrm{H}_{14} \mathrm{~S}_{2}, \mathrm{C}_{15} \mathrm{H}_{26} \mathrm{O}, \mathrm{C}_{6} \mathrm{H}_{10} \mathrm{O}, \mathrm{C}_{7} \mathrm{H}_{12} \mathrm{O}, \mathrm{C}_{10} \mathrm{H}_{16} \mathrm{O}$, $\mathrm{C}_{17} \mathrm{H}_{31} \mathrm{Br}$ and $\mathrm{C}_{13} \mathrm{H}_{14} \mathrm{O}$ identified only when cultured with DMSO. Compounds $\mathrm{C}_{9} \mathrm{H}_{12} \mathrm{O}_{3}$, $\mathrm{C}_{8} \mathrm{H}_{12} \mathrm{O}_{2}, \mathrm{C}_{16} \mathrm{H}_{32} \mathrm{O}_{2}, \mathrm{C}_{15} \mathrm{H}_{26} \mathrm{O}$ and $\mathrm{C}_{18} \mathrm{H}_{26} \mathrm{~N}_{2} \mathrm{O}$ were specifically produced by $A$. niger in presence ethanol while, $\mathrm{C}_{2} \mathrm{H}_{2} \mathrm{O}, \mathrm{C}_{15} \mathrm{H}_{26} \mathrm{O}, \mathrm{C}_{16} \mathrm{H}_{32} \mathrm{O}_{2}, \mathrm{C}_{18} \mathrm{H}_{34} \mathrm{O}_{2}, \mathrm{C}_{10} \mathrm{H}_{15} \mathrm{NO}_{3}, \mathrm{C}_{3} \mathrm{H}_{6} \mathrm{O}_{2}$, $\mathrm{C}_{7} \mathrm{H}_{10} \mathrm{~F}_{2} \mathrm{O}, \mathrm{C}_{17} \mathrm{H}_{16} \mathrm{O}_{6}$ and the unknown compound were stimulated only in the presence of 5azacytidine (Table 1).

\section{Discussion}

Aspergillus niger (Ascomycota) is one of the most pharmaceutical friendly organisms that produce industrially important enzymes as well as bioactive secondary metabolites. It has proven high potential in producing antimicrobial compounds (Magnuson \& Lasure 2004, Nielsen et al. 2009). However, new insights into the molecular biology of this fungus have demonstrated that its genetic potential in terms of producing a greater chemical diversity of compounds has been vastly underestimated in the past (Fisch et al. 2009). The culture of microorganisms with small organic chemicals has been proposed to stimulate the silent genes in order to produce new secondary metabolites (Pettit 2011). Therefore, this study was designed to study the effect of acetone, DMSO, ethanol and 5-azacytidine on the production of volatile and non-volatile metabolites by an endophytic strain of Aspergillus niger in culture.

The results achieved in this study indicated that the tested small chemicals have significant impact on the qualitative and quantitative diversity of volatile and non-volatile secondary metabolites produced by A. niger. These findings corroborate previous reports by many authors who claimed that $A$. niger is an outstanding biosynthetic source of compounds (Fisch et al. 2009, Nielsen et al. 2009, Richter et al. 2014, Al-Shaibani et al. 2013, Siddiquee et al. 2015). The studies by Siddiquee et al (2015) and Hameed et al (2015) also reported rich metabolites diversity though, they were different from those identified in our study given the differences in A. niger origin, the formulation of PDB used, culture conditions, the extraction procedure and GC-MS analysis. In our study, the A. niger strain was an endophyte isolated from a plant, Terminalia catappa where the secondary metabolism is known to be different from that of terrestrial saprobic species (Strobel and Daisy 2003).

The HPLC profile of ethyl acetate extract of fungus cultured in the presence of acetone, showed in addition to the peaks found in control (untreated A. niger), one new peak at 35.87 minutes. Similarly, Guo et al (2014) reported that acetone was able to stimulate the production new metabolites by Eupenicillium sp. With ethanol as elicitor, one new peak was detected at 38.05 minutes in the HPLC profile while, 13 volatile compounds not found in control were identified with GC-MS analysis. Ethanol was also found by Cueto et al. (2001) to elicit the synthesis of a new chlorinated benzophenone antibiotic, pestalone, by the marine fungus Pestalotia. The HPLC profile of the extract from DMSO treatment showed an inhibition of the production of several compounds, and one new peak was detected at 38.05 
minutes. On the contrary, the GC-MS profile showed the presence of 16 volatile metabolites of which 15 were not found in the control, suggesting that the presence of DMSO in PDB might have directed the secondary metabolism to the synthesis of volatile instead of nonvolatile compounds. The GC-MS profile of extract from culture of A. niger with 5azacytidine showed the presence of 13 compounds with one new compound detected at 26.683 minutes with $0.83 \%$ abundance. The 5-azacytidine, a DNA methyltransferase inhibitor, has previously been reported to stimulate the synthesis of new secondary metabolites in fungi (William et al. 2008, Henrikson et al. 2009).

Comparison of the intensities of different compounds detected with HPLC and the abundance of volatile compounds identified with GC-MS indicated that the rate of production of some compounds is elicitor-specific. In fact, the production of 1-undecyne was $1.36 \%$ in the presence of ethanol, and more than doubled when supplemented with DMSO $(2.74 \%)$. Similar compositional variation trends were observed with many other components such as 5,6-dichlorohexene that increased from $0.2 \%$ with ethanol to $4.87 \%$ with 5 -azacytidine; Lproline, $\mathrm{N}$-valeryl-, undecyester that also increased to $3.63 \%$ with 5 -azacytidine supplementation from $0.75 \%$ with DMSO and $0.21 \%$ with ethanol and 3isopropyl[3]manxine-6,9-diol that increased to $3.67 \%$ with 5 -azacytidine from $0.37 \%$ with ethanol. Such variation also concerned Cyclohexanecarboxaldehyde,3,3-dimethyl-5-oxo- that was highly produced in the presence of ethanol $(64.38 \%)$ in comparison to DMSO $(40.12 \%)$ and acetone $(58.21 \%)$.

\section{Conclusion}

This study has demonstrated that small organic chemicals such as acetone, ethanol, DMSO, and 5-azacytidine can elicit the production of secondary metabolites by the endophytic A. niger. On a general point of view, this finding suggests a possible biotechnological application of these chemicals to increase the yield of specific compounds. This approach has shown promise, and has the potential to be exploited in the search for new bioactive chemical scaffolds against a large array of diseases.

\section{Acknowledgments}

The authors are grateful to the Research training fellowship for developing country scientists (RTF-DCS) 2015 - 2016 granted to the first author and to Advanced Instrumental Research Facility of Jawaharlal Nehru University for GC-MS analysis of samples.

\section{References}

Al-Shaibani ABA, Al-Shakarchi FI, Ameen RS. 2013 - Extraction and Characterization of Antibacterial compound from Aspergillus niger. Journal of Al-Nahrain University16 (4), 167-174.

Baker D, Mocek U, Garr C. 2000 - Natural products vs. combinatorials: a case study, p. 6672. In S. K. Wrigley, M. A. Hayes, R. Thomas, E. J. T. Chrystal, and N. Nicholson (ed.), Biodiversity: new leads for pharmaceutical and agrochemical industries. The Royal Society of Chemistry, Cambridge, United Kingdom.

Bode HB, Bethe B, Höfs R, Zeeck A. 2002 - Big effects from small changes: possible ways to explore nature's chemical diversity. ChemBioChem 3, 619-627.

Brakhage AA, Schroeckh V. 2011 - Fungal secondary metabolites-strategies to activate silent gene clusters. Fungal Genet Biol. 48, 15-22. doi:10.1016/j.fgb.2010.04.004

Combès A, Ndoye I, Bance C, Bruzaud J, Djediat C, Dupont J,Nay B, Prado S, Chaturvedi V. 2012. - Chemical communication between the endophytic fungus Paraconiothyrium 
variabile and the phytopathogen Fusarium oxysporum. PLoS One. 7:e47313. doi:10.1371/journal.pone.0047313

Cueto M, Jensen PR, Kauffman C, Fenical W, Lobkovsky E, Clardy J. 2001 - Pestalone, a new antibiotic produced by a marine fungus in response to bacterial challenge. Journal of Natural Products 64, 1444-1446.

De la Cruz M, Martín J, González-Menéndez V, Pérez-Victoria I, Moreno C, Tormo JR, El Aouad N, Guarro J, Vicente F, Reyes F, Bills GF. 2012 - Chemical and physical modulation of antibiotic activity in Emericella species. Chem Biodivers. 9, 10951113. doi:10.1002/cbdv.201100362

Fisch KM, Gillaspy AF, Gipson M, Henrikson JC, Hoover AR, Jackson L. 2009 - Chemical induction of silent biosynthetic pathway transcription in Aspergillus niger. J Ind Microbiol Biotechnol 36, 1199-1213.

Gao L, Sun MH, Liu XZ, Che YS. 2007 - Effects of carbon concentration and carbon to nitrogen ratio on the growth and sporulation of several biocontrol fungi. Mycol Res 111, 87-92.

Guo Na, Ya Liu, Xing Y, Peng Y. 2014 - Induced formation and characterization of a citreoisocoumarin derivative by a new-isolated Eupenicillium sp. in the presence of dimethyl sulfoxide or acetone. Journal of Chemical and Pharmaceutical Research, 20, 6(6), 2607-2609.

Hameed IH, Hamza LF, Kamal SA. 2015 - Analysis of bioactive chemical compounds of Aspergillus niger by using gas chromatography-mass spectrometry and fouriertransform infrared spectroscopy. Journal of Pharmacognosy and Phytotherapy. Vol. 7(8), 132-163. DOI: 10.5897/JPP2015.0354

Henrikson JC, Hoover AR, Joyner PM, Cichewicz RH. 2009 - A chemical epigenetics approach for engineering the in situ biosynthesis of a cryptic natural product from Aspergillus niger. Org Biomol Chem7, 435-438.

Klich MA, 2002 - Identification of Common Aspergillus species.Ponsen \& Looijen, The Netherlands.

Kumar CG, Mongolla P, Joseph J, Nageswar YVD, Kamal A. 2010 - Antimicrobial activity from the extracts of fungal isolates of soil and dung samples from Kaziranga National Park, Assam, India. J Med Mycol 20, 283-289.

Magnuson J, Lasure L. 2004 - Organic acid production by filamentous fungi. In: Tkacz, J., Lange, L. (Eds.), Advances in Fungal Biotechnology for Industry, Agriculture, and Medicine. Kluwer Academic \& Plenum Publishers, New York, 307-340.

Maria GL, Sridhar KR, Raviraja NS. 2005 - Antimicrobial and enzyme activity of mangrove endophytic fungi of southwest coast of India. J Agric Technol 1, 67-80.

Marmann A, Aly AH, Lin W, Wang B, Proksch P. 2014 - Co-Cultivation-A Powerful Emerging Tool for Enhancing the Chemical Diversity of Microorganisms. Mar. Drugs 12, 1043-1065. doi: 10.3390/md12021043

Nielsen KF, Mogensen JM, Johansen M, Larsen TO, Frisvad JC. 2009 - Review of secondary metabolites and mycotoxins from the Aspergillus niger group. Anal Bioanal Chem. 395(5), 1225-1242.

Payne GA, Nierman WC, Wortman JR, Pritchard BL, Brown D, Dean RA. 2006 - Whole genome comparison of Aspergillus flavus and A. oryzae. Med Mycol 44, S9-S11.

Pettit RK. 2011 - "Small-molecule elicitation of microbial secondary metabolites," Microbial Biotechnology 4(4), 471-478.

Richter L, Wanka F, Boecker S, Storm D, Kurt T, Vural Ö, Süßmuth R, Meyer V. 2014 Engineering of Aspergillus niger for the production of secondary metabolites. Fungal Biology and Biotechnology 1, 4. 
Sánchez Márquez S, Bills GF, Zabalgogeazcoa I. 2007 - The endophytic mycobiota of the grass Dactylis glomerata. Fungal Diversity 27, 171-195.

Scherlach K, Hertweck C. 2009 - Triggering cryptic natural product biosynthesis in microorganisms. Org Biomol Chem 7, 1753-1760. Doi: 10.1039/b821578b

Schneider P, Misiek M, Hoffmeister D. 2008 - In vivo and in vitro production options for fungal secondary metabolites. Mol Pharm 5, 234-242.

Schulz B, Boyle C, Draeger S, Rommert AK, Krohn K. 2002 - Endophytic fungi: a source of novel biologically active secondary metabolites. Mycological Research. 106, 9961004.

Siddiquee S, Al Azad S, AbuBakar F, Naher L, Kumar VS. 2015 - Separation and identification of hydrocarbons and other volatile compounds from cultures of Aspergillus niger by GC-MS using two different capillary columns and solvents. Journal of Saudi Chemical Society 19, 243-256

Strobel G, Daisy B, Castillo U, Harper J. 2004 - Natural products from endophytic microorganisms. Journal of Natural Products 6, 257-268.

Strobel G, Daisy B. 2003 - Bioprospecting for microbial endophytes and their natural products. Microbiology and Molecular Biology Reviews 67(4), 491-502.

Tan RX, Zou WX. 2001 - Endophytes: a rich source of functional metabolites. Natural Product Reports 18, 448-459.

Tayung K, Jha DK. 2007 - Antimicrobial activity of a compound produced by Aspergillus sp. DEF 505, an endophyte on Taxus baccata. J Microbial World 9, 287-292.

Toghueo RMK, Zeuko'o Menkem E, Mbekou Kanko MI, Jesus Marie Arc-en-Ce, Ngo Mback N, Eke P, Vázquez de Aldana BR, Íñigo Z, Fekam Boyom F. 2016 Antimicrobial and antiradical activities of ethyl acetate extracts from endophytic fungi isolated from Cameroonian medicinal plants. Journal of Medicinal Plants Studies 4(4), 290-295.

Wang J, Huang Y, Fang M, Zhang Y, Zheng Z, Zhao Y, Su W. 2002 - Brefeldin A, a cytotoxin produced by Paecilomyces sp. and Aspergillus clavatus isolated from Taxus mairei and Torreya grandis. FEMS Immunol Med Microbiol 34, 51-57.

White TJ, Bruns T, Lee S, Taylor J. 1990-Amplification and direct sequencing of fungal ribosomal RNA genes for phylogenetics. In: PCR protocols. A guide to methods and applications (eds. M.A. Innis, D.H.Gelfland, J.J. Sninsky, T.J. White). Academic Press, USA: $315-322$.

Williams RB, Henrikson JC, Hoover AR, Lee AE, Cichewicz RH. 2008 - Epigenetic remodeling of the fungal secondary metabolome.Org Biomol Chem 6, 1895-1897.

Zerikly M, Challis GL. 2009 - Strategies for the discovery of new natural products by genome mining. Chem Bio Chem 10, 625-633. doi:10.1002/cbic.200800389

Zhang HW, Song YC, Tan RX. 2006 - Biology and chemistry of endophytes. Natural Product Reports 23, 753-771. 